\title{
ON SOME FURTHER HYPERGEOMETRIC SERIES IDENTITIES OBTAINED VIA FRACTIONAL CALCULUS
}

\author{
S. GABOURY And A. K. RAThiE
}

Abstract. In this paper we present a generalization of a result obtained recently by Rathie and Kiliçman (A. K. Rathie and A. Kiliçman, On certain new hypergeometric identities, Preprint 2014) involving hypergeometric identities. The result is obtained by suitably applying fractional calculus technique to a generalization of a quadratic transformation for the Gauss hypergeometric function due to Gauss.

Mathematics subject classification (2010): Primary 26A33, 33C90, 33C05; Secondary 33C70.

Keywords and phrases: Fractional derivatives, generalized hypergeometric function, Gauss quadratric transformation formula, beta integral method.

\section{REFERENCES}

[1] A. ERdÉLYI, An integral equation involving Legendre polynomials, SIAM J. Appl. Math. 12 (1964), $15-30$.

[2] B. C. Berndt, Ramanujan's Notebooks, Parts II, Springer-Verlag, Berlin, Heidelberg and New York, 1989.

[3] J. Choi And A. K. Rathie And H. M. SRivastava, Certain hypergeometric identities deducible by using the beta integral method, Bull. Korean Math. Soc. 50 (2013), 1673-1681.

[4] E. D. Rainville, Special Functions, Macmillan Company, New York, 1960.

[5] S. GABOURY AND A. K. RATHIE, Further hypergeometric identities deducible by fractional calculus, Commun. Korean Math. Soc. 29, 3 (2014), 429-437

[6] S. Gaboury and A. K. Rathie, Certain hypergeometric series identities deducible by fractional calculus, Preprint, 2014.

[7] S. GABOURY AND R. TREMBlay, Remark on certain transformations for multiple hypergeometric functions, Adv. Difference Equ., Preprint 2014, 1-13.

[8] A. K. Ibrahim And M. A. Rakha And A. K. Rathie, On certain hypergeometric identities deducible by using the beta integral method, Adv. Difference Equ. 361 (2013), 1-8.

[9] J. LiouviLle, Mémoire sur le calcul des différentielles à indices quelconques, J. de l'École Polytechnique 13 (1832), 71-162.

[10] A. A. Kilbas and H. M. SRivastava And J. J. Trujillo,, Theory and Applications of Fractional Differential Equations, North-Holland Mathematical Studies (Jan van Mill ed.), Vol. 204, Elsevier (North-Holland) Science Publishers, Amsterdam, London and New York, 2006.

[11] C. KRATtenthaleR AND K. S. RAO, Automatic generation of hypergeometric identities by the beta integral method, J. Comput. Appl. Math. 160 (2003), 159-173.

[12] E. E. Kummer, Über die hypergeometrische Reihe $1+\frac{\alpha \beta}{1 \cdot \gamma} x+\frac{\alpha(\alpha+1) \cdot \beta(\beta+1)}{1 \cdot 2 \cdot \gamma(\gamma+1)} x^{2}+\cdots$, J. Reine Angew. Math. 15 (1836), 39-83 and 127-172.

[13] J.-L. Lavoie and T. J. Osler And R. TRemblay, Fundamental properties of fractional derivatives via Pochhammer integrals, Lecture Notes in Mathematics, Springer-Verlag, 1976.

[14] M. RiesZ,,L'intégrale de Riemann-Liouville et le problème de Cauchy, Acta. Math. 81 (1949), 1-222.

[15] K. S. Miller And B. Ross, An Introduction of the Fractional Calculus and Fractional Differential Equations, New York, Chichester, Brisbane, Toronto and Singapore, John Wiley and Sons, 1993, Wiley, New York. 
[16] R. TREmblay, Une contribution à la théorie de la dérivée fractionnaire, Laval University, Canada, 1974.

[17] M. A. Rakha, Generalization of a quadratic transformation due to Gauss, Int. J. Math. Math. Sci. 2012, 1-16, Article ID 789519.

[18] A. K. RATHIE AND A. KiliçMAn, On certain new hypergeometric identities, Preprint, 2014.

[19] A. K. RATHIE AND Y. S. KIM, On two results contiguous to a quadratic transformation due to Gauss, Far East J. Math. Sci. 31 (2011), 51-58.

[20] H. M. Srivastava And J. Choi, Zeta and q-Zeta Functions and Associated Series and Integrals, Elsevier Science Publishers, Amsterdam, London and New York, 2012.

[21] T. J. OSLER, Leibniz rule, the chain rule and Taylor's theorem for fractional derivatives, Ph.D. thesis, New York University, 1970.

[22] T. J. OsLer, Fractional derivatives and Leibniz rule, Amer. Math. Monthly 78 (1971), 645-649.

[23] T. J. OSLER, Leibniz rule for the fractional derivatives and an application to infinite series, SIAM J. Appl. Math. 18 (1970), 658-674.

[24] T. J. OSLER, Fractional derivatives of a composite function, SIAM J. Math. Anal. 1 (1970), $288-293$.

[25] C. WEI AND X. WANG AND Y. LI, Certain transformations for multiple hypergeometric functions, Adv. Difference Equ. 360 (2013), 1-13. 